\title{
High School Students' Attributions of success in English Language Learning
}

\author{
Benzehaf Bouchaib \\ Chouaib Doukkali University, El Jadida, Morocco, bbenz841@gmail.com \\ Bouylmani Ahmadou \\ Chouaib Doukkali University, El Jadida, Morocco,ahmadoub@gmail.com \\ Sabil Abdelkader \\ Chouaib Doukkali University, El Jadida, Morocco,abdelkadrs@gmail.com
}

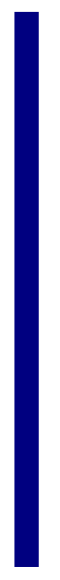

\begin{abstract}
Research into students' attributional causes for success in language acquisition is currently receiving considerable attention. Situated within Weiner's attribution theory (1992), the present study aims to research factors contributing to success in foreign language learning with specific focus on the role of perceived causal attributions. The participants are 113 students from three high schools in El Jadida, Morocco. The instrument of data collection is a questionnaire and a follow-up interview. More specifically, the participants identify the causes that they think lead to success in English language learning and make an evaluation of themselves in respect of whether they think they are successful EFL learners thus far. Findings from both data sets show that students attribute success in foreign language learning mostly to external factors with class atmosphere and teaching method ranking highest. Also, a significant difference is noted between students who perceive themselves as 'successful' and those who perceive themselves as 'unsuccessful' in terms of effort and time distribution in learning English. In light of the results, important implications are drawn for different stakeholders.
\end{abstract}

Keywords: foreign language learning, self-evaluation, success, failure, attributional causes

\section{INTRODUCTION}

In the age of globalization, characterized by the English language gaining a high level of international significance which enabled it to become the lingua franca, the potential of the ELT pedagogy for restructuring existent power relationships cannot be overestimated. However, at the very time the demand for English is increasingly becoming higher, the standard of English teaching and learning in our Moroccan schools is being widely criticized. To confirm the unsatisfactory proficiency levels in English,

Citation: Bouchaib, B., Ahmadou, B., \& Abdelkader, S. (2018). High School Students' Attributions of success in English Language Learning. International Journal of Instruction, 11(2), 89-102. https://doi.org/10.12973/iji.2018.1127a 
Morocco came $44^{\text {th }}$ according to EF English proficiency index ${ }^{1}$ (2016) with an average score of 49.86 which is categorized as low proficiency. Thus, urgent action is required to remedy the situation and prepare our students for functioning in this intercultural global universe. But this action requires a priori diagnosis of the problems affecting the English language teaching/learning environment which lie behind such generally low proficiency levels.

So far, much of the debate about foreign language education reform in Morocco has focused on the efficacy of teaching methodologies at the neglect of contextual factors individual, social, societal and situational which have their important share in the current standards of language that our students have. These factors can be incorporated in the category of motivation which constitutes the primary impetus for getting engaged in the language learning process. Of equal importance and bearing on language learning, though not in a clear and direct way, are students' beliefs about the language, learning and attributional causes for success/failure, variables which are currently receiving considerable attention in educational research.

The power of people's beliefs is widely discussed and recognized in both educational and social psychology. Students' language beliefs are so important that their proficiency levels can be assumed to be no more than a reflection of what they think and believe with regard to their ability to learn the language. According to Dörnyei (2001), students' beliefs and the way students interpret past behaviours and actions can obviously impact their present and future behaviours. In Flavell's view (1987), beliefs are considered as part of metacognitive knowledge that students bring with them to the classroom. It goes without saying that metacognitive knowledge plays a facilitative role in language learning. Accordingly, we can reasonably assume that beliefs can explain why students who are exposed to a language do not attain homogeneous proficiency levels. It is, therefore, important to acknowledge the importance of Moroccan EFL students' beliefs and to know them particularly with regard to perceived causes of success because such knowledge can help us deal with the beliefs according to their nature to support and increase learning.

It is in view of these facts that a plethora of studies in different areas of education have been conducted to investigate learners' perceived causality of success and failure in language learning. These studies have been informed by attribution theory (Weiner, 1972, 2000) which provides insight into why some students are always successful while others are doomed to fail. Researchers turned to attribution theory because of its potential to empower educators to help more students succeed by emphasizing internal

\footnotetext{
${ }^{1}$ EPI is the first index of its kind that gives countries a benchmark against which to measure the average English competency among adult speakers. It is the product of EF Education First, an international education company headquartered in Switzerland, and is concerned with identifying the countries with the highest proficiency of English as a second language based on data collected from English tests on the Internet.
} 
controllable factors such as effort and strategy. In the context of Morocco, however, and to our best knowledge, there is a paucity of studies which probe students' causal attributions in foreign language learning. Hence and in support of the power of beliefs, this study aims to investigate Moroccan high school students' perceived causes of success in learning English. In particular, it addresses three research questions:

1. To what factors do students attribute success in English language learning?

2. How different are the causal attributions between self-rated successful and selfrated unsuccessful students?

3. How does perceived success influence students' distribution of time and effort in learning English?

\section{THEORETICAL FRAMEWORK}

The study is situated within the constructivist paradigm which places a high premium on the social dimension in knowledge construction, meaning making and attribution creation. More specifically, the study is couched within the theoretical framework of attribution theory. This theory helps provide explanations or reasons for people's successes or failures in education. Essentially, attribution theory which is pioneered by Weiner $(1972,2000)$ is a social cognitive theory of motivation. The basic claim of it is that retrospective causal attributions have an impact on present and future motivation and achievement. The theory has located causal attributions along three dimensions: locus, stability and controllability. Locus of causality refers to internal versus external causes; stability indicates whether or not the perceived causes of success or failure are permanent/lasting or temporary/fluctuating; while controllability is about whether or not individuals have control over the causes. Weiner also believed that four main factors impact attributions which he placed within these dimensions, namely: ability, effort, task difficulty and luck.

According to attribution theory, learners are active participants in knowledge construction through interaction with their environment on the one hand, and with their pre-existing knowledge and beliefs on the other hand. Attribution theory helps explain the difference in motivation between high and low second/foreign language learning achievers. According to this theory, high achievers believe success is due to high ability and effort and are consequently oriented towards success-related tasks, whereas low achievers have the tendency to doubt their ability and/or assume success is related to factors beyond their control. Ability and effort constitute internal attributional factors which motivate students to be focused on their learning. In line with this claim, Gardner (1985, p. 10) defines motivation as a notion which "refers to the combination of effort plus desire to achieve the goal of learning the language plus favorable attitudes toward learning the language".

It is noteworthy that attributions are not accurate reflections of reality but perceived causes of success based on self-evaluations. But these perceived attributions are more important in attribution theorists' views than actual reasons. Their importance stems from the fact that unlike syllabus content which is fixed and quite unchangeable, attributions are flexible enough to be changed in such a way as to enhance language learning. The formation of attributions can be viewed as a way of adapting to changing 
environments and overcoming the challenges faced with in language education programs. Attributions, therefore, need first to be identified and then interventions are required according to their nature and in a way that promotes healthy learning behaviours and demotes unhealthy actions. In educational settings, attribution theory has been used to investigate perceived causes for success and failure in academic achievement. For instance, if a student has developed an unhealthy set of attributions to account for his/her failure, it is possible, by means of attribution, to reorient him/her to think in a more positive way.

\section{LITERATURE REVIEW}

Different studies have been conducted which investigated students' attributional causes of success and failure in foreign language learning. The purpose was to identify second or foreign language learners' attributions for success and failure and to assess the correlation between attributions and good academic achievement. Weiner's attribution theory has been used as a frame of reference in these studies because it is considered the most complete attribution framework. Questionnaires were the main research instrument used in these studies and the results identified a number of different factors as the most common explanations of success in foreign language learning. Some of these factors were internal (motivation, ability, effort), while others were external (teacher influence, and classroom atmosphere).

Some studies showed that students with good proficiency levels made internal attributions while students with low proficiency levels made more external attributions. For instance, Adiba (2004) reported that high achievers attributed their performances to ability and effort as internal attributions and low performers attributed their achievements to task difficulty and luck as external attributions. Similarly, Hsieh (2004) reported that the learners who made internal, stable and personal attributions were more successful than the learners who attributed success to external, unstable, and nonpersonal attributions. In a similar vein, Kun and Liming (2007) found that the learners who attributed success to internal factors were more self-regulated learners.

However, a second category of studies also emphasized the role of external factors in achieving success in language learning. For instance, Gobel and Mori (2007) investigated perceived reasons for success and failure in the skills of speaking and reading and reported that self-rated poor performers attributed their poor performance to lack of ability and effort, whereas self-perceived high performers attributed their performance to teachers and the classroom atmosphere. Similarly and through the instrument of case study research design, Yan and Li (2008) examined SLA learners' conceptions of causal attributions and found that the learning environment and teachers can deeply influence students' motivation to learn a foreign language.

Along the same lines, Thepsiri and Pojanapunya (2010) reported in their study on university students' attributions that grades, teacher influence, and classroom atmosphere were the main factors that facilitated success, while lack of ability, inappropriate learning strategy, lack of preparation, and lack of effort were described as failure attributions. They also found that the level of proficiency was a factor influencing the formation of different views on attributions for success and failure. 
Two other studies which have tried to specify second/foreign language learners' attributions and the effect of perceived attributions on learners' language learning outcomes were conducted by Peacock (2010) and Yazdanpanah, Sahragard, and Rahimi (2010) respectively. Both studies reported significant relationships between attributions and EFL proficiency. In particular, Peacock reported statistically significant differences between attribution and EFL proficiency, gender, and academic discipline and between student and teacher opinions. Yazdanpanah et al. concluded that the locus of control was significantly related to students' academic achievement and predictive of it.

In another comparative study that utilized the attribution-to-success-and-failure questionnaires, Gobel, Thang, Sidhu, Oon and Chan (2013) researched the differences existing between Malaysian urban and rural students in perceived causes of success and failure in English language learning. A significant difference was reported between urban and rural groups, with urban students being more willing to believe in their own ability, effort, and study skills than rural students. The findings also suggested a close correlation between urban students' success attributions with high proficiency levels as the majority of the high proficient students were from the urban group. The researchers concluded that confidence and positive attitudes towards learning English comes with high proficiency.

In the same vein, Gaerlan (2016) investigated the causes of failure in learning in English and found that in addition to lack of effort, another main cause of failure as perceived by poor learners was the language learning environment mainly because of overcrowded classrooms. Along the same lines, Genç (2016) analyzed Turkish tertiary level EFL learners' attributions to success and failure and the effects of gender, age, and perceived success on their attributions. The main finding was that EFL learners were more inclined to attribute success to internal factors while blaming external reasons for their failure.

In the context of Morocco, Bzioui (2017) investigated Moroccan university successful students' attributions for success in English through the means of a questionnaire. His participants came from different higher education schools: engineering, business, science and arts. Interestingly, the findings arrived at indicated that the successful students overwhelmingly were self-motivated to learn English and they learnt it from watching movies. The next factors that impacted on their learning were teacher positive feedback and good exam grades. The researcher concluded that there are three factors that contribute to good English language learning among successful students in Morocco, namely positive attitude, input and practice.

All in all, the studies can be divided into two categories. An important part establishes a strong causal relationship between internal causal attributions and academic achievement. Accordingly, the implications that were drawn in these studies focused on the necessity to help learners shape positive beliefs about the causes of success and failure in foreign language education, mostly to emphasize the role of internal factors because, unlike external factors, these can be controlled and geared towards successful language learning. On the other hand, a second category of studies suggested that successful learners do not make only internal attributions but also external attributions, thus attaching importance and showing recognition to teachers' role in successful language learning. In view of these different findings, one is tempted to assume that 
attributions may also be culture-specific, though further research is to be conducted before this conclusion is finally sanctioned. Against this background, this study aims at probing Moroccan high school learners' perceived causes for success/failure in learning English as a foreign language.

\section{METHOD}

The purpose of this study is to build upon emerging research into aspects of students' attributions for their perceived causes of success and failure in foreign language learning. In particular, this study is concerned with examining high school students' attributions for their success or failure in English language learning, and the extent to which these attributions vary across self-rated successful and self-rated unsuccessful students. A further focus is on the dimensions of locus, stability and controllability. The main motivation behind this focus is the idea that these dimensions dictate the type of interventions needed to promote healthy learning behaviours. To meet that end, we decided to use a mixed-methods approach, namely questionnaires, which have been widely used in attribution research, and interviews, which we used to follow up on the questionnaires by way of further explaining the outcomes obtained. Such a mixed methods approach also enabled us to obtain results from different perspectives and to triangulate findings obtained from quantitative data.

\section{Participants}

We enlisted a sample of 113 high school second year baccalaureate students, 51 males and 62 females, from three high schools within the province of El Jadida in the academic year 2016-2017. We delivered the questionnaire in February, 2017 and had interviews with twenty students in March, 2017. The schools selected in the study are Lycée 6 Novembre in Ouled Frej, Lycée Moulay Abdella in Moulay Abdella, and Lycée Chouaib Doukkali in El Jadida. Female participants made up 54.9\% of the whole sample while male participants constituted $45.1 \%$ of the sample. The participants had an age range of 16-18. They were randomly selected and, we believe, they represented the whole population of successful and unsuccessful language learners. We randomly picked numbers from each school which were computer generated and then recruited the students who matched the numbers.

\section{Research design}

The important variables investigated are perceived attributional causes of English language learning success/failure. To pursue this aim, we chose a survey research design as a method of collecting the necessary data. There are reasons that motivated our choice of this research design: first, survey designs have the advantage of being quite easy to develop and administer; second, they are considered an effective means of gathering information about causal attributions of success as they are quick and economical with respect to materials, money and time; third, they are reliable and easily quantifiable. That explicates the reason why attribution research has used them as the main data collection instrument.

\section{Data collection method}

The present study used a questionnaire and a semi-structured interview. After consulting attribution theory and surveying the different studies conducted on perceived causes for 
success in foreign language learning, we decided that self-report questionnaires could serve as the best instrument to identify students' perceived causes for success in learning English. It is noteworthy that most similar studies used this instrument and some even used readymade questionnaires which have been designed by some researchers based on attribution theory, like the "Attribution to Success and Failure Questionnaires" (ASQ \& AFQ), based on research conducted by Vispoel and Austin (1995). Thus, we designed a Likert-scale questionnaire consisting of attributions which aimed at eliciting the participants' levels of agreement. We administered the questionnaire in class after assuring the participants of the confidentiality of the information and giving them the choice to participate or refrain.

The questionnaire used in this study is in two parts. The first part elicited demographic information about the participants while the second part included attributional Likert-scale items expressed in terms of degree of agreement: Strongly Agree (SA), Agree (A), Neutral $(\mathrm{N})$, Disagree (D), and Strongly Disagree (SD). The benefit of a Likert-scale questionnaire is that it quantifies information as it enables the calculation of means and standard deviations, thus facilitating observation and comparison of findings with findings of other studies. Although we designed the questionnaire in English, we supplied an Arabic version of it so that all participants could understand its content and what it required of them ${ }^{2}$.

In addition to items about demographic information and the question eliciting amount of time and effort exerted in language learning, the questionnaire consisted of nine Likert scale items based on the domains identified by Weiner's attribution theory as responsible for success/failure attributions. Five of these attributions were based on external factors while the remaining items were internal. With regard to the validity of the questionnaire, after we made it consistent with attributional questionnaires used in other studies, we sought expert opinion. Two researchers examined it for readability, feasibility, wording clarity, and layout and style. They also gave their expert opinion on the relevance of the items to the domain. The percentage of the items deemed relevant or very relevant was $99 \%$. Then, we subjected the questionnaire items to Cronbach's Alpha which yielded a reliability score of ",88".

As a follow-up to the questionnaire, we also conducted an interview with twenty of the participants to fill any gaps left, clarify answers and triangulate data. Interviews are important for this purpose. We chose the semi-structured type of interview because it helps provide clues into the reality of students' attributions, thus filling any gaps that might have arisen from utilizing the questionnaire. Unlike the structured interview which uses questions followed by choices from which the interviewee selects the answer, the semi-structured interview does not provide answers, thus allowing for free individual responses. It, therefore, allows the researcher to have free access to people's minds particularly if it is conducted in an informal setting (Nunan, 1992).

\section{FINDINGS}

\section{Causal attributions for success in English language learning}

The first research question elicited participants' attribution causes for success in English language learning. More specifically, students were asked to indicate their level of agreement with a number of attributions of success. We computed the means and

\footnotetext{
${ }^{2}$ The Arabic version was just a supplementary for any lack of understanding of items in English.
} 
standard deviations of the answers of the participants. The following table illustrates students' answers:

Table 1

Attributional causality for success

\begin{tabular}{llllll}
\hline & $\mathrm{N}$ & Minimum & Maximum & Mean & Std. Dev. \\
\hline teacher influence & 113 & 3,00 & 5,00 & 4,34 &, 60 \\
class atmosphere & 113 & 1,00 & 5,00 & 4,23 &, 72 \\
task difficulty & 113 & 2,00 & 5,00 & 3,56 &, 88 \\
personal ability & 113 & 2,00 & 5,00 & 3,55 &, 87 \\
interest/motivation & 113 & 1,00 & 5,00 & 3,30 & 1,11 \\
personal effort & 113 & 2,00 & 5,00 & 3,24 &, 82 \\
Strategy & 113 & 1,00 & 5,00 & 3,01 &, 92 \\
peer influence & 113 & 1,00 & 4,00 & 2,90 &, 89 \\
sheer luck & 113 & 1,00 & 5,00 & 1,91 &, 92 \\
Valid N (listwise) & 113 & & & & \\
\hline
\end{tabular}

Obviously, external factors ranked highest as attributions for success. Teacher influence (with a mean of 4,34) and classroom atmosphere (a mean of 4,23) came at the top of the list of attributions followed by task difficulty (a mean of 3,56). As for internal factors, they came next and they were ability (a mean of 3,55), interest (a mean of 3,30) and effort (a mean of 3,24) in this order. Strategy also had an important mean of 3,01 while luck came last with a weak mean $(1,91)$. The standard deviations were small indicating absence of large variations among the participants.

\section{Difference between self-rated successful and self-rated unsuccessful students}

The second research question investigated the differences between perceived causes of success in English language learning between self-rated successful students and selfrated unsuccessful students. Table 2 below provides the results obtained.

Table 2

Difference between self-rated successful and unsuccessful students

\begin{tabular}{|c|c|c|c|c|}
\hline & & $\mathrm{N}$ & Mean & Std. Deviation \\
\hline \multirow{2}{*}{ personal ability } & successful students & 52 & 4,09 & ,72 \\
\hline & unsuccessful students & 61 & 3,09 & ,72 \\
\hline \multirow{2}{*}{ sheer luck } & successful students & 52 & 1,86 & ,95 \\
\hline & unsuccessful students & 61 & 1,95 & ,90 \\
\hline \multirow{2}{*}{ personal effort } & successful students & 52 & 3,78 &, 74 \\
\hline & unsuccessful students & 61 & 2,78 &, 58 \\
\hline \multirow{2}{*}{ task difficulty } & successful students & 52 & 3,26 & ,88 \\
\hline & unsuccessful students & 61 & 3,81 &, 80 \\
\hline \multirow{2}{*}{ Strategy } & successful students & 52 & 3,40 & ,89 \\
\hline & unsuccessful students & 61 & 2,68 & ,82 \\
\hline \multirow{2}{*}{ interest/motivation } & successful students & 52 & 3,94 &, 50 \\
\hline & unsuccessful students & 61 & 2,77 & 1,20 \\
\hline \multirow{2}{*}{ teacher influence } & successful students & 52 & 4,36 &, 52 \\
\hline & unsuccessful students & 61 & 4,32 & 67 \\
\hline \multirow{2}{*}{ class atmosphere } & successful students & 52 & 4,11 & 67 \\
\hline & unsuccessful students & 61 & 4,34 &, 75 \\
\hline \multirow{2}{*}{ peer influence } & successful students & 52 & 2,69 & ,94 \\
\hline & unsuccessful students & 61 & 3,08 & ,82 \\
\hline \multirow{2}{*}{ time distribution } & successful students & 52 & 4,30 & 67 \\
\hline & unsuccessful students & 61 & 2,04 & ,82 \\
\hline
\end{tabular}


Fifty-two participants rated themselves as low achievers while sixty-one self-perceived as high achievers. The table above shows that the means for internal factors were higher for self-rated successful learners than for self-rated unsuccessful learners. Successful students got a mean of 4,09 in personal ability while unsuccessful learners received 3,09 . In effort, self-rated successful learners got 3,78 while unsuccessful students got 2,78. Along the same lines, 3,94 was the mean of successful learners in interest whereas unsuccessful learners got only 2,77 . However, the means in teacher influence and class atmosphere were quite close for both successful and unsuccessful students (4,36 versus 4,32 and 4,11 versus 4,34 respectively).

To test the significance of the observed differences in the means of both groups of students, we conducted an independent-samples t-test. Table 3 below shows that there was a significant difference in the scores of self-rated successful learners and the scores of self-rated unsuccessful learners in personal ability, personal effort, task difficulty, strategy and interest/motivation. However, no statistically significant differences were noted between the two groups with regard to the other attributions.

Table 3

Independent Samples Test

\begin{tabular}{|c|c|c|c|c|c|c|}
\hline & & $\mathrm{F}$ & Sig. & $\mathrm{t}$ & df & Sig. (2-tailed) \\
\hline \multirow[t]{2}{*}{ personal ability } & Equal variances assumed & ,056 & ,814 & 7 & 111 & ,000 \\
\hline & Equal variances not assumed & & & 7 & 108 & ,000 \\
\hline \multirow[t]{2}{*}{ personal effort } & Equal variances assumed & 1,084 & ,300 & 7 & 111 & 000 \\
\hline & Equal variances not assumed & & & 7 & 95 & 000 \\
\hline \multirow[t]{2}{*}{ task difficulty } & Equal variances assumed & 1,415 & ,237 & -3 & 111 & 001 \\
\hline & Equal variances not assumed & & & -3 & 104 & ,001 \\
\hline \multirow[t]{2}{*}{ Strategy } & Equal variances assumed &, 184 & ,669 & 4 & 111 & ,000 \\
\hline & Equal variances not assumed & & & 4 & 105 &, 000 \\
\hline \multirow[t]{2}{*}{ interest/motivation } & Equal variances assumed & 113,024 & ,000 & 6 & 111 &, 000 \\
\hline & Equal variances not assumed & & & 6 & 82 & ,000 \\
\hline \multirow[t]{2}{*}{ time distribution } & Equal variances assumed &, 012 & ,913 & 15 & 111 &, 000 \\
\hline & Equal variances not assumed & & & 16 & 110 &, 000 \\
\hline
\end{tabular}

Students' distribution of time and effort

The last research question probed differences between self-rated successful students and self-rated unsuccessful students with regard to effort and time distribution. Answers showed that successful students allocated more time to their language studies than unsuccessful students. The mean of the successful group was 4,30 versus 2,04 for the unsuccessful group. The t-test that we conducted indicated that this difference was statistically significant, $\mathrm{t}(111)=16$.

\section{Results of interview}

Twenty student participants were randomly selected to take part in the interview. They were equally divided between males and females and for practical reasons were from the same school, 6 Novembre high schools where one of the researchers works. Twelve of them self-rated as successful while eight self-rated as unsuccessful. All interviewees were given the same questions in the questionnaire and answers generally came in support of those obtained in the questionnaire. For instance, all the interviewees indicated that the teacher influenced their performance with his/method of teaching and 
the type of rapport s/he kept with students. One of the interviewees commented: "the teacher encourages or discourages you to study"; another added, "it is the teacher who makes you love or hate the subject". Class atmosphere, ability, interest and task difficulty were also mentioned in this order.

Regarding effort and time distribution, twelve students who indicated they were successful said that they always ( 8 interviewees) or usually (4 interviewees) revised lessons and did extra activities that promoted their English language learning. For instance, a female student said, "I watch films in English and try to learn new words from them"; the others all claimed they listened to songs in English and learnt from them vocabulary". One student said, "I practice English every day because I love it". Such high levels of time and effort distribution on the part of successful students were not shared by the students who perceived themselves as unsuccessful. Specifically, eight interviewees indicated they found difficulty with the language; in particular, 6 indicated that they rarely revised their English language lessons while the remaining 2 said they sometimes revised their language lessons. One of the interviewees who claimed they rarely reviewed their language lessons, a female, said she hardly revised English, "why should I read something I do not understand? " she said in Arabic. A second student, a male, blamed the teacher and the teaching material for his low proficiency level. He said, "the texts we should read are difficult and the teacher does not do anything to help us understand." He added that the teacher should translate the difficult words in Arabic so that they could understand. He indicated that even when he read, he would not understand anything.

\section{DISCUSSION}

This study has tried to investigate the factors that cause success in English language learning from the perspective of students. In pursuing that aim, the study has used attribution theory as a framework which helps not only to provide insight into students' perceived causes for success and failure in foreign language education, but also to use the perceived causes of success to induce more success and to make more students successful. The study also probed the differences between self-rated successful students and self-rated unsuccessful students with regard to these attributions and with regard to effort and time distribution. To that end, it used two data collection tools, namely the questionnaire and the interview. The results obtained show that all students, successful and unsuccessful, place a high premium on external variables as factors that promote success in English language learning. However, successful students also view internal factors, such as ability and effort, as important in language learning. Following is a table outlining the factors deemed most important in success in English language learning and the dimensions along which they are grouped according to attribution theory:

Table 4

Attributions of success and dimensions

\begin{tabular}{llllll}
\hline $\begin{array}{l}\text { Attribution/ } \\
\text { Dimension }\end{array}$ & $\begin{array}{l}\text { Teacher } \\
\text { influence }\end{array}$ & $\begin{array}{l}\text { Class } \\
\text { atmosphere }\end{array}$ & Ability & Interest & Effort \\
\hline Locus & External & External & Internal & Internal & Internal \\
\hline Stability & Stable & Stable & Stable & Unstable & Unstable \\
\hline Controllability & Uncontrollable & Uncontrollable & Uncontrollable & Controllable & controllable \\
\hline
\end{tabular}


According to the table which classifies the attributions according to attribution theory, it is obvious that all students give importance to factors that are external, stable and uncontrollable. That teachers and class atmosphere constitute important causal factors in language learning is not something new. It corresponds with findings of previous studies. For instance, Thang et al. (2011) also reported teacher influence to be one of the most endorsed attributes for success in addition to "getting a good grade". Similarly, Yan and Li (2008) found that teachers and the language environment can have a great influence on students' foreign language achievement.

However, while teachers can have a great influence on students, impacting on their learning, effort and motivation to learn a foreign language, caution must be taken. The danger of attributing success only to external factors lies in the fact that so far as the students put the responsibility on other factors that are external to them and which they cannot control, their achievement will not be within their hands and thus they will not make any effort. Thus, it is the teachers' duty to sensibilize them to the importance of internal factors in building success.

Moving to differences between self-rated successful and self-rated unsuccessful students, it becomes clear that self-rated successful students are different in a strategic way from selfperceived unsuccessful students in that they are aware of the role of internal factors. By also attributing success to internal factors, these students can link academic achievement to effort and proper learning strategies (Weiner, 2006), thus viewing their learning outcomes as controllable and changeable. In so doing, students can exert more effort in future learning if they want higher grades and greater likelihood of success.

The results clearly show that self-rated successful learners rate strategy, ability and effort higher than self-rated unsuccessful learners. The differences have also been found to be statistically significant between the two groups with regard to these internal factors. A possible interpretation of this finding is that perceived successful learners recognize that they can continue to achieve high as long as they put effort into learning and use the right learning strategies. Interest is another internal factor that significantly distinguishes successful learners from unsuccessful ones. Thus, interest can help students improve as well. These findings are also consistent with the literature. Hsieh (2004) also reported that successful learners make more internal, personal, and stable attributions. Similarly, Abida (2004) reported that good students made internal attributions while poor learners attributed their achievements to external factors like task difficulty, and so did Genç (2016) who investigated Turkish tertiary level EFL learners' attributions. He reported that EFL learners were more inclined to attribute success to internal factors while blaming external reasons for their failure. Interestingly, the findings are also consistent with those obtained in Bzioui's study. Bzioui reported that Moroccan successful students attribute success primarily to their high motivation/interest (an internal attribution) followed by teacher positive feedback and good exam grades (external attributions).

By and large, the findings obtained in this study are empirically supported. Different studies have more or less come to the same conclusion. Noteworthy also is the fact that the findings are also theoretically supported, though only partially so. Attribution theory has it that learners make different attributional causes and that those who make more internal controllable attributions are more successful than the learners who make more external uncontrollable attributions. According to attribution theory, high achievers believe success is 
due to high ability and effort and are oriented towards success-related tasks while low achievers tend to doubt their ability and/or assume success is related to uncontrollable factors. It is not surprising, therefore, that self-rated successful learners in this study have indicated that they exert more effort in and allocate more time to their English language studies. Consistent with the theory, the difference between the two groups in effort and time distribution has been found to be statistically significant. It follows, therefore, that self-rated successful students can control the outcome of their learning while self-perceived unsuccessful learners continue to blame external factors for their failure. However, inconsistent with the theory, self-perceived successful learners made also external attributions, thus acknowledging the important role of the environment within which language learning takes place.

\section{CONCLUSION AND IMPLICATIONS}

The present study revealed that Moroccan high school students have certain attributions for success in English language learning. The top attributions are teacher influence and classroom atmosphere followed by more internal factors like ability, interest, effort and strategy. The study also revealed that self-rated high achievers make more internal attributions and allocate more time to their English language studies than perceived low achievers. In light of these findings, a set of implications are in order.

The teachers' duty is to emphasize internal, unstable and controllable attributions as key drivers of language learning. Equally important, the teacher has to convince the students of the consequences of using appropriate learning strategies and exerting their fullest potential to succeed in learning English. The teachers should convince their students that achievement is not only influenced by teachers, but is also an individualistic process that students must take into their own hands in order to control and promote their learning outcomes. The necessity of effort in language learning should be instilled in the learners and this is a task that teachers should assume together with parents. On their part, learners are called upon to put more effort in their learning, use appropriate learning strategies, and exhibit more interest in acquiring the language.

The teachers are also called on to create a more supportive learning environment which is learner-centered. In this context, Littlewood (1984) reports that class atmosphere retains a positive impact on learning English as a foreign language. A relaxed atmosphere should, therefore, prevail in the classroom which makes learning enjoyable. Positive rapport should characterize the relation holding between teachers and students so as to build their selfconfidence. Above all, the classroom should be a supportive environment where students are free to make mistakes and learn from them.

On the part of policy making, there is the need to design a language education program that is centered not only on teaching efficacy but also on other equally important variables. These are the non-linguistic part of any language education program which contributes highly to the success of language learning as they constitute the contextual factors within which the language is taught/learnt. More particularly, these variables are students' beliefs, attributions, positive attitudes to language studies and interest. It is noteworthy that these factors are constructed from a constructivist perspective, thus the need to be sensitive to them and respond to them according to their nature.

This study has implications also for the theory within which the study is situated. Attribution theory makes the claim that successful learners tend to make internal attributions to success 
while unsuccessful learners make external attributions. The findings of this study corroborated findings obtained in other studies (for instance, Bzioui, 2017; Gobel \& Mori, 2007; Thang et al, 2011; Thepsiri \& Pojanapunya, 2010) which showed that successful learners attribute success to a combination of internal and external factors. In view of this, we are inclined to make the conclusion that attributions may also be culture and/or subject related. Other studies, though, are highly desirable before this conclusion is finally accredited.

Lastly, perceived causal attributions and students' beliefs may seem unscientific. However, it is perceived causality more than reality that matters in such events of learning. When a student perceives something as a hindrance, then learning will not occur unless that perceived hindrance is removed. Also, it is always meaningful to examine students' views, beliefs, attitudes, preferences and perceived causes of success as the findings can provide insight into how to go about language learning and make it more successful, thus the importance of such studies. Williams, Burden, Poulet and Maun (2004) report that studies of this nature can help improve classroom management in such a way as to support and enhance foreign language education. In closing, further research using different data collection methods and targeting different learner groups is desirable so that deeper insights are provided into causal attributions which are to be acted on with the purpose of ameliorating English language learning and raising proficiency levels.

\section{REFERENCES}

Adiba, F. (2004). Study of attributions of low achievers and high achievers about the perceived causes of their success and failure. Ph.D. dissertation, University of Arid Agriculture, Rawalpindi.

Bzioui, A. (2017). English language teaching in Morocco: Unheeded messages. A paper presented at the colloquium "Issues in English language teaching: Theory and practice" held at the Faculty of education, Rabat, May 18-19, 2017.

Dörnyei, Z. (2001). Motivational strategies in the language classroom. Cambridge: Cambridge University Press.

Flavell, J.H. (1987). Speculation about the nature and development of metacognition. In F.E. Weinert \& R.H. Kluwe, (Eds.), Metacognition, motivation and understanding (pp. 1-29). Hillsdale, NJ: Lawrence Erlbaum.

Gaerlan, M. J. (2016). Learning in a L2: An analysis of less successful Filipino ESL learners' experiences through Consensual Qualitative Research. Paper presented at the DLSU Research Congress De La Salle University, Manila, Philippines, March 7-9, 2016.

Gardner, R. C. (1985). Social psychology and second language learning: the role of attitudes and motivation. London: Edward Arnold.

Genç, G. (2016). Attributions to success and failure in English language learning: The effects of gender, age and perceived success. European Journal of Education Studies, 2(12), 25-43.

Gobel, P., \& Mori, S. (2007). Success and failure in the EFL classroom: Exploring students' attributional beliefs in language learning. In L. Roberts, Leah, A. Gürel, S. Tatar \& L. Marti (Eds.), EUROSLA Yearbook 7 (pp. 149-169). Amterdam: John Benjamins Publishing Company. 
Gobel, P., Thang, S. M., Sidhu, G. K., Oon, S. I., \& Chan, Y. F. (2013). Attributions to success and failure in English language learning: A comparative study of urban and rural undergraduates in Malaysia. Asian Social Science, 9(2), 53-62.

Hsieh, P. H. (2004). How college students explain their grades in a foreign language course: The interrelationship of attributions, self-Efficacy, language learning beliefs, and achievement. (Unpublished doctoral dissertation). University of Texas, Austin.

Kun, L., \& Liming, Y. (2007). The influence of achievement attributions on self-regulated language learning behaviors. CELEA Journal, 30(1), 82-89.

Littlewood, W.T. (1984). Foreign and Second Language Learning. Cambridge University Press.

Nunan, D. (1992). Research Methods in Language Learning. Cambridge: Cambridge University Press.

Peacock, M. (2010). Attribution and learning English as a foreign language. ELT Journal, 64(2), 184-193.

Thang, S. M., Gobel, P., Mohd, N. F., \& Suppiah, V. L. (2011). Students' attributions for success and failure in the learning of English as a second language: A comparison of undergraduates from six public universities in Malaysia. Pertanika J. Soc. Sci. \& Hum, 19(2), 459-474.

Thepsiri, K., \& Pojanapunya, P. (2010). Science and Engineering Students' Attributions for Success and Failure in the EFL Classroom. The Journal of Asia TEFL,7(3), 29-57.

Vispoel, W., \& Austin, J. (1995). Success and failure in junior high school: A critical incident approach to understanding students' attributional beliefs. American Educational Research Journal, 32(2), 377-412.

Weiner, B. (1972). Theories of Motivation: From Mechanism to Cognition. Chicago: Markham Publishing Company.

Weiner, B. (2000). Intrapersonal and interpersonal theories of motivation from an attributional perspective. Educational Psychology Review, 12(1), 1-14.

Weiner, B. (2006). Social motivation, justice, and the moral emotions: An attributional approach. Mahwah, NJ: Lawrence Erlbaum Associates.

Williams, M., Burden, R., Poulet, G., \& Maun, I. (2004). Learners' perceptions of their successes and failures in foreign language learning. Language Learning Journal, 30, 19-29.

Yan, H., \& Li, X. (2008). Causal Attribution and its Conceptions by Non-English Major Postgraduates in China: A Case Study. Asian Social Science, 4(4), 77-80.

Yazdanpanah, M., Sahragard, R., \& Rahimi, A. (2010). The interplay of locus of control and academic achievement among Iranian English foreign language learners. Cypriot Journal of Educational Sciences, 5, 181-202. 